\title{
Assessing social cognitive functions in elementary school children: or problems of motor activity disorders
}

\section{Evaluación de las funciones cognitivas sociales en niños de escuela primaria: o problemas de trastornos de la actividad motora}

Received: January 18, 2021

\begin{abstract}
The urgency of the research issue is due to the tendency of an increase in the number of children with disorders of the muscle-skeleton system and motor skills. In this regard, these children have problems in learning activities, relationships with peers and adults. The purpose of the research presented in the paper was to study the social and psychological peculiarities of the personality of elementary school children with motor activity (motor skills) disorder. To solve the tasks set in the study and test the hypothesis, a number of methods and techniques were used: theoretical analysis of scientific literature, empirical methods: observation, experiment, questionnaire, technique of N.I. Ozeretsky; children's version of S. Rosenzweig's test; "school-based anxiety" test. The study revealed that two options are possible in the development of the personality of elementary school children with motor activity disorders: favorable and unfavorable. An unfavorable variant of the child's personality development is associated with "non-constructive" behavior, which manifests in the inability to withstand difficult social situations. A favorable variant of personal development is characterized by the predominance of "constructive" behavior, which allows one to overcome life difficulties.
\end{abstract}

Accepted: March 3, 2021

Written by:

Vladimir Eliseev ${ }^{43}$

https://orcid.org/0000-0003-2002-0431

Irina Eliseeva ${ }^{44}$

https://orcid.org/0000-0003-4178-8140

Maria Korobova ${ }^{45}$

https://orcid.org/0000-0002-4093-7434

Julia Romanova ${ }^{46}$

https://orcid.org/0000-0002-7302-4658

\section{Resumen}

La urgencia del tema de la investigación se debe a la tendencia al aumento del número de niños con trastornos del sistema músculo-esquelético y de las habilidades motoras. En este sentido, estos niños tienen problemas en las actividades de aprendizaje, las relaciones con sus compañeros y con los adultos. El propósito de la investigación que se presenta en el artículo fue estudiar las peculiaridades sociales y psicológicas de la personalidad de los niños de la escuela primaria con trastorno de la actividad motora (habilidades motoras). Para resolver las tareas planteadas en el estudio y probar la hipótesis, se utilizaron una serie de métodos y técnicas: análisis teórico de la literatura científica, métodos empíricos: observación, experimento, cuestionario, técnica de N.I. Ozeretsky; versión infantil de la prueba de S. Rosenzweig; prueba de "ansiedad basada en la escuela". El estudio reveló que dos opciones son posibles en el desarrollo de la personalidad de los niños de la escuela primaria con trastornos de la actividad motora: favorable y desfavorable. Una variante desfavorable del desarrollo de la personalidad del niño se asocia con "comportamiento", que se manifiesta en la incapacidad para soportar situaciones sociales difíciles. Una variante favorable del desarrollo personal se caracteriza por el predominio del

\footnotetext{
${ }^{43}$ Prof., DSc, Lipetsk of State Pedagogical University, Russia.

${ }^{44}$ Docent, PhD, Lipetsk of State Pedagogical University, Russia

${ }^{45}$ Docent, PhD, Lipetsk of State Pedagogical University, Russia.

${ }^{46}$ Docent, PhD, Lipetsk of State Pedagogical University, Russia.
} 
Key Words: behavior disorders, cognitive functions, elementary school children, personal development.

\section{Introduction}

Motor activity and motor development, in particular, are an integral part of personality development in general. The most important social and psychological problems of personality formation in ontogenesis: motivational-activitysphere, intelligence, mastering new types of behavior, self-adjustment are considered in the psychological and pedagogical literature in close connection with the development of motor skills. The social and psychological peculiarities of children with motor disorder studying in mainstream general education schools, who are not registered in medical records, are obviously insufficiently studied. Crudity of this problem results in unjustifiably broad generalizations about the unambiguously negative impact of motor development disorders not only on the academic progress of schoolchildren, but also on their mental appearance, the nature of relationships with other people, primarily teachers and classmates. The very likelihood for the appearance of a favorable variant of the personality development of elementary school children in such objectively difficult social conditions is excluded.

Disorders of individual motor characteristics of an elementary school child (strength, accuracy, coordination), to which educational activity makes special demands, are most significant for the development of a child's personality. The problem of the research is that disorders of the indicated parameters of motor development can result in both favorable and unfavorable variants of personality development, depending on the social and psychological, and pedagogical conditions of their formation. Based on the analysis of the scientific problem, we formulated its goal and the main objectives of this study. The purpose of the research was to study the social and psychological peculiarities of the personality of elementary school children with motor activity - motor skill - disorder. The research hypothesis is based on the idea that motor skills development plays an essential role in the formation of the child's personality. At primary school age, those characteristics of motor skills are especially significant that are required by educational activities, namely: accuracy, coordination, strength of movements. We comportamiento "constructivo", que permite superar las dificultades de la vida.

Palabras clave: trastornos de conducta, funciones cognitivas, niños de escuela primaria, desarrollo personal.

assumed that these motor disorders can result in both a negative scenario of personal development and, under certain conditions, not have a significant negative effect on it. To test the hypothesis, the following research objectives were identified: to experimentally study the behavior of elementary school children with motor disorder in difficult life social situations; study the features of the emotional background of these children; to analyze the peculiarities of the attitude of persons under testing towards themselves and to other people; to conduct a comparative analysis of the social and psychological peculiarities of the personality of the studied school children with favorable and unfavorable variants of personality development; to identify pedagogical conditions contributing to the favorable personality development of children with motor disorders.

The key to uncover the psychological mechanisms of the influence of motor development disorders on the personality of an elementary school child, in our opinion, lies in the analysis of the connection between motor disorders and the child's affection in society. However, at a certain period, thanks to physical activity, the child himself tries to expand the horizon for getting new impressions. Motor disorders make this process more difficult. An adult physically limits the range of influencing impressions on a child. The need without confirmation begins to weaken. As a result, a low level of aspirations and a passive personal position are formed. It is important for a child that the activities performed are appreciated by adults, but usually appreciation of their work by adults is rather low. The child's emotional state depends on how they react to them. A negative role in the personality formation is played not so much by the defect itself as by the painful responses of others; in addition, people who tend to overvalue the severity of their own state are distinguished by self- depreciation, a narrowed range of interests, and an orientation toward "benign" conditions. A child of elementary school age is intensively involved in relationships with peers. Children with motor disorders differ from their peers in clumsiness, so they are often not accepted into games. While 
analyzing the ways of children behavior in frustration situations, we can conditionally divide them into "constructive" and "nonconstructive". "Constructive" is such a child's behavior strategy, which combines activity, consciousness, adequacy, purposefulness in overcoming the objective and subjective difficulties of the situation. This behavior strategy (Rosenbaum, 2005) corresponds to the "principle of reality" and contributes to the situation change and transformation into its positive version. Among the modes of behavior that can be called "non-constructive", most authors mention, first of all, the mechanisms of psychological defense. The "non-constructive" behavior provokes deviations and deformations in personality development.

\section{Literature Review}

According to some foreign studies, the personality problems of children with motor disorders lie in the emotional, cognitive, and behavioral spheres. K. Adolph and J. Hoch (2019) suppose the motor and psychological development is an ideal model system for studying personality development. A. Cummins, J. Piek and M. Dyck (2005) point to emotional difficulties, poor social skills, and low empathic abilities of children with motor skill disorder. A. Diamond (2000) emphasizes the equally longterm periods of motor and cognitive development. D. Rigoli, J.P Pieks (2020) associate the presence of motor disorders with cognitive and social skills. D. Green, G. Baird, and D. Sugden (2006) state the relationship between motor disorders and emotional and behavioral symptoms. A. Poulsen, J. Ziviani, M. Cuskelly and R. Smith (2007) correlates coordination difficulties with loneliness. B. Provost, R. Lopez and S. Heimerl (2007) emphasize that these children have autistic spectrum disorders. S. Rahimi-Golkhandan, B. Steenbergen, J. Piek and P. Wilson (2014) state that they have an increased social sensitivity. C. Von Hofsten (2004); H. Krombholz (2018); R. Gerber, T. Wilks and C. Erdie-Lalena (2010) emphasize disturbances in the processes of perception, planning and motivation. M. Wagner, K. Bös, J. Jascenoka, D. Jekauc and F. Petermann (2012); J. van der Walt, N. Plastow and M. Unger (2020); O. Gasser-Haas, F. Sticca and C. Seiler, (2020) point to the problems of communication with peers. C. Kopp (2011); E. Skinner and M. Zimmer-Gembeck (2020); C. Heiman, W. Cole, D. Lee and K. Adolph (2019) associate high physical activity with the possibility of self- affirmation. P. Wehmeier, A. Schacht and R. Barkley (2010); J. Piek, L. Dawson, L. Smitha and N. Gasson (2008) note the social and communication difficulties of these children. F. Fulceri, E. Grossi, A. Contaldo, A. Narzisi, F. Apicella, I. Parrini, R. Tancredi, S. Calderoni and F. Muratori (2019) also believe that motor, cognitive and social skills develop in parallel in children. M. Cantell, M. Smyth, T. Ahonen (1994); K. Lee, Y. Kim, Y. Lee (2020) pay attention to lowering their interest in social hobbies and low academic ambitions for their future. M. Francis, J. Piek (2003) associate motor disorders in this category of children with a high level of depressive symptomatology. A. Losse, S. Henderson, D. Elliman, D. Hall, E. Knight, M. Jongmans (1991) - with low self-esteem and various problems at school. M. Mokobane, B. Pillay, A. Meyer (2019); P. Jansen, C. Quaiser-Pohl, S. Neuburger, V. Ruthsatz (2015); M. Lezak, D. Howieson, D. Loring, H. Hannay, J. Fischer (2004) associate such motor skill disorders as hyperactivity primarily with the cognitive activity of the individual in the educational process. J. Goodway, J. Ozmun, D. Gallahue (2019) and Corbetta (2010) believe that motor activity disorders are associated primarily with psychomotor personality development in children of different ages. Scientists S. King-Dowling, M. Kwan, C. Rodriguez, C. Missiuna, B. Timmons, J. Cairney (2019) share this opinion.

In foreign scientific literature, children with motor activity (motor skill) disorders are often presented as "clumsiness". In studies of foreign psychologists devoted to the so-called "clumsy" children, they have noted not only cognitive difficulties, but also interpersonal communication, as well as negative subjective experiences about their defects. R. Lord, C. Hulme (1987); C. Downing, M. Caravolas (2020) found deviations of the indices of visualspatial perception in "clumsy" children. O. Schabos, K. Hoffmann, B. Enzi, G. Juckel, P. Mavrogiorgou (2020) point to the association of coordination and clumsiness with intellectual disabilities. M. Schoemaker, A. Kalverboer (1994) point that "clumsy" children are more introverted; they consider themselves less competent both physically and socially. R. Skinner and J. Piek (2001) believe they have lower self-esteem and higher levels of anxiety.

\section{Methodology}

To study the psychological peculiarities of children with motor disorders and in accordance 
with the goals and objectives of this study, the following methods were used: children's "Rosenzweig's Picturesque Frustration" text form (1945), "school-based anxiety" test. Comparison of the results of all methods allowed, firstly, to characterize the personal characteristics of children with motor disorders and to identify individual variants for manifestation of emotional well-being; secondly, to trace the relationship of this well-being with the characteristics of the child's relationship with reference persons: peers, parents, teachers in society. The subjects were a group of 42 secondgrade pupils with motor development disorders trained in mainstream general education schools in Lipetsk and the Lipetsk Region. This group of schoolchildren was formed as a result of selection according to N.I. Ozeretsky (1930). The obtained indicators of physical activity were compared with the standard ones. The study was conducted in 2019-2020. The analysis of scientific literature on this topic allows us to emphasize the importance of the problem of motor disorders for the personality development of an elementary school child. Motor disorders make it difficult for a child to learn - the solution of the most important task of elementary school age as a stage in the life path of an individual. Therefore, motor skill disorder can significantly deform a child's personal development. However, it should be emphasized that motor disorders have a negative impact on the personality development also through a complex system of experiences caused by the child's position in the system of social relationships. Thus, behavior in a difficult social situation can be "constructive" and "non-constructive". The "constructive" behavior is associated with selfconfidence, active desire to meet needs, reflects the ability to overcome obstacles and contributes to the personality development. The "nonconstructive" behavior is associated with aggressive or avoidant responses to barriers and can result in disturbance of personality development in society.

\section{Results and Discussion}

According to the results of S. Rosenzweig's test, all children were divided into 3 groups: I. "constructive" group, which included children with preponderance of constructive responses over non-constructive ones; II. - "nonconstructive" group, which consisted of children with a predominance of non-constructive types of responses over constructive ones; III "unidentifiable" group represented by children, who do not show a predominance of any type of response. We referred to a comparison of children belonging to the "constructive" (I) and "non-constructive" (II) groups. From the point of view of the degree and nature of motor disorders, the selected groups are practically homogeneous. Average indicators of test performance according to N.I. Ozeretsky (1930) were: in group I -7 (range 5-9), and in group II - 8 (range 5-10) with a standard value of $11-14$ points. The differences between them are not statistically significant. Disorders in all children, both in group I and group II differ in such components of movement as speed, dynamic coordination, coordination of the right and left hands, accuracy. The medical examination has showed that the children of these groups also do not differ among themselves in terms of such indicators as weight, height, vital lung capacity, general well-being and physical growth and development level. Therefore, we have reason to consider the selected groups to be homogeneous in terms of medical and biological indicators, as well as indicators of motor disorders, and to compare them with each other according to the psychological peculiarities of interest to us.

We analyzed the results of S. Rosenzweig's Picturesque Frustration test by orientations, types and kinds of individual responses based on comparing the two indicated groups with each other and with the age norm. The group response profiles were plotted based on individual results (Fig.). 


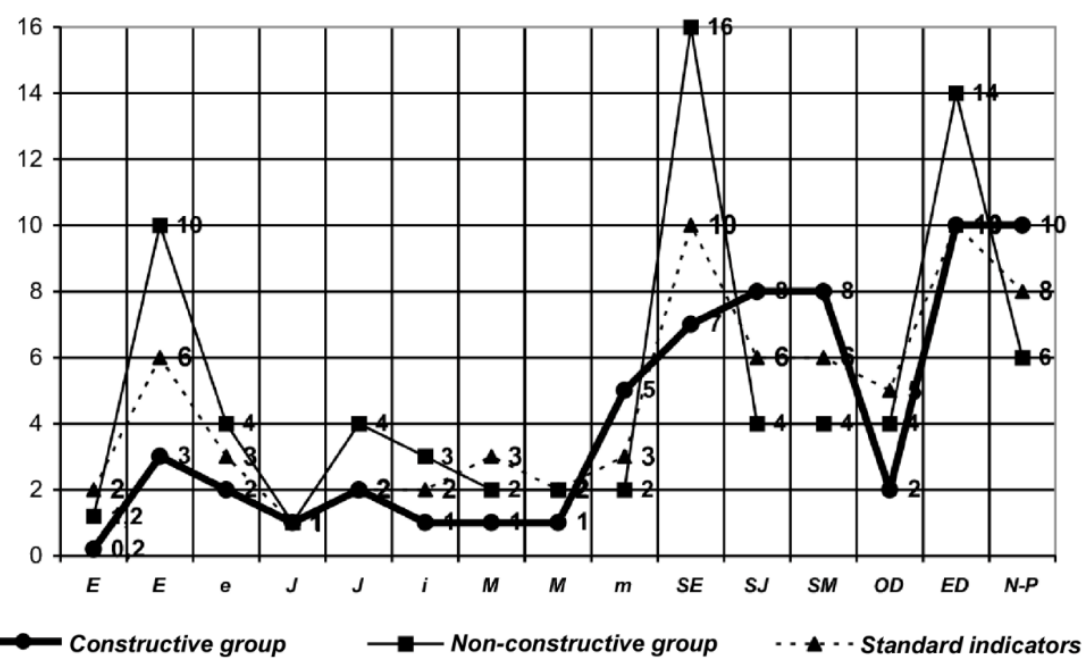

Figure. Responses profile according to the S. Rosenzweig's test. Source: the autor.

Responses of an impunitive and intropunitive orientation significantly predominate in "constructive" group of children (although in both groups they are within the normal range). Thus, these children showed greater evidence in comparison with the "non-constructive" ones, requirements for themselves, accession to obligation. This group of children also tends to minimize the traumatic unpleasant aspects of difficult situations and decelerate external targeted responses where "non-constructive" children usually express their demands in an extrapunitive manner. According to $\mathrm{S}$. Rosenzweig, the assessment of this type of responses indicates to what extent the subject is able to resolve frustrating situations. This type of responses is higher in terms of values in children of group I and it prevails over the assessments of other responses, which is a clear sign of their typical response to frustration. In addition, the lower values of responses with fixation on a barrier (O-B) were noted in children of group I, which expresses a low degree of inclination of this children category to focus on the existing barriers in situations of frustration and thus performs a protective function from negative experiences.

In children of group II ("non-constructive"), extrapunitive responses (E) predominate, i.e. responses to others. This means, that children specify exclusive standards to other people in a situation of frustration. Moreover, if the "constructive" children have the number of these responses within the age norm, then it is significantly higher for the "non-constructive" children and exceeds the norm. The "nonconstructive" children tend to solve difficult situations by increasing demands on others, to change their behavior. The main contribution to the assessment of extrapunitive responses in children of group 2 is made by responses against someone or something. Hostility, censure, blame are the forms in which children require others to change their behavior to resolve a situation. Hostility and anger cause discontent among people around, which cannot but affect the emotional well-being of the child. Such children tend to emphasize the presence of a barrier (E) with remarks in which a feeling of confusion and hopelessness is expressed. Similar feelings arise from their involvement in the frustration of another person.

The described responses are more rarely in children of group I. In contrast to group II, they have the most pronounced desire to address the problem of frustration situation themselves. The children's responses indicate confidence in the ability to overcome difficulties generating positive feelings. The expression of hope for the normal course of events is associated with them, automatic resolution of a problem through mutual understanding and mutual compliance. This behavior assumes great compliance, intouch capabilities of children, mutual understanding with other people, which indicate a favorable personality development.

At the same time, the children of group I have the higher indicators of the response of taking the fall. However, many of the children's answers are a variant of this type of response, which reflect not just an admission of guilt, but a call for mitigating circumstances, therefore, can help to maintain a positive mood. More often, the 
"demand" or "expectation" response profiles express the hope that someone else will solve the situation. With regard to such temporary ways for achieving emotional well-being as negation of a frustrating situation (M) or minimizing the responsibility and avoidance of condemnation (M), then the assessments of these responses practically do not differ in the studied groups and correspond to the norm. They are not the main factor in the emotional well-being regulation, since, if they contribute to maintaining the emotional well-being but for a very short time, not solving the problem, but only postponing it. This behavior can both contribute and hinder emotional well-being.

It is interesting to compare these groups according to the criterion of the ratio of different response types expressed in indices, for example, in the index of aggressive trend, which reflects the aggression trend towards oneself, initially directed outward. The aggression trend indices were: in group I - 0.9; in group II - 4.0. In case of normal personality development, the index value shall be close to one, because excessive self-accusation and external aggressiveness are destructive for the individual.

In children of group I, the number of accusatory responses corresponds to the number of selfaccusations. Children of group II show increased aggression. Aggression is always a defense that does not contribute to the favorable personality development. The "problem solving" index reflects a child's desire to resolve a difficult situation on his/her own without external help. The index value is significantly higher in children of group I compared with group II (0.9 and 0.2 , respectively). In children of group I, the number of responses in which the child tries to solve a difficult situation on his/her own is approximately equal to those situations in which he/she demands that someone else would propose a resolution. In children of group II, independent responses are significantly less.

These data indicate a rather high dependence of all children with motor disorders on adults, which is explained by the peculiarities of their upbringing and development. Parents, seeing the clumsiness of the child, for a long time perform many actions for him/her, considering this as a manifestation of love. However, this dependence can become neurotic, dangerous for the personality development and lead to a disturbance in child affection, neuroses. A higher level of independence in children of group I contributes to maintaining emotional well-being. The behavior of children in the "constructive" group depends on the situation content. According to the content, the situations are divided into situations of interaction with adults and situations of interaction with peers. Our study detected the predominance of "constructive" behavior in children of group I in situations of interaction with adults.

An in-depth study of behavior in the situation of frustration of children of the constructive group has revealed that there are gender differences within this group. The comparative data on the severity of different types of reactions in boys and girls of the constructive group in the average parameters of frequency of occurrence are given in Table.

Table.

Average indicator of different reactions types in boys and girls constructive group. Source: the author.

\begin{tabular}{|c|c|c|}
\hline \multirow{2}{*}{ Type of reaction } & \multicolumn{2}{|c|}{ Test group } \\
\hline & Boys & Girls \\
\hline $\mathrm{E}^{\prime}$ & 0,4 & 1 \\
\hline $\mathrm{E}$ & 4,1 & 3,4 \\
\hline $\mathrm{e}$ & 2,2 & 2,8 \\
\hline$\Sigma \mathrm{E}$ & 6,7 & 7,2 \\
\hline$I^{\prime}$ & 0,6 & 0,3 \\
\hline I & 3,4 & 5,5 \\
\hline $\mathrm{i}$ & 5,0 & 2,2 \\
\hline$\Sigma \mathrm{I}$ & 9,0 & 8,0 \\
\hline$M^{\prime}$ & 2,9 & 1,7 \\
\hline M & 0,8 & 1.5 \\
\hline $\mathrm{m}$ & 4,6 & 5,4 \\
\hline$\Sigma \mathrm{M}$ & 8,3 & 8,6 \\
\hline O-D & 3,9 & 3,0 \\
\hline E-D & 8,3 & 10,4 \\
\hline N-P & 11,8 & 10,4 \\
\hline
\end{tabular}


Legend:

\section{Reaction trend:}

E - extrapunitive responses

I - intropunitive responses

$\mathrm{M}$ - impunitive

Types of reactions:

OD - fixing on a barrier

ED - fixing on self-defense

$\mathrm{NP}$ - fixing to meet the need

O-D - barrier-dominant

E-D - ego-protective

N-P - need-unstable

$E^{\prime}$ - the presence of a frustrating circumstance

I' - a frustrating situation is interpreted as favorable or as a condign punishment

$\mathbf{M}^{\prime}$ - denies the significance or unfavorableness of the barrier

$\mathrm{m}$ - a subject hopes for a successful resolution of problems in due coarse

$\mathrm{i}-$ a subject, recognizing its responsibility

$\Sigma-$ amount

The results analysis shows that both boys and girls demonstrate the most "constructive" behavior in a situation with an adult, and such type of behavior as justification, application for help prevails in both boys and girls (I). In the latter type of situations, there is more often a response of the M-P type with fixation on meeting needs, i.e. both boys and girls strive to fulfill their plans and do not give up their intentions. In this case, the means to the end are used the same as in the situations of interaction with adults. I would like to emphasize that intrapunitive responses are much less common, especially the self-protective type, which are usually very often used in situations with adults. The manifestations of such features of intropunitive protective behavior of children of both sexes are also mentioned in the papers (Provost, Lopez and Heimerl, 2007). Children gang up on conflict with their peers, express aggression, but not just as self-defense, but in order to resolve the situation. Similar symptoms of "clumsy children" are noted in their studies by D. Green, G. Baird and D. Sugden (2006), who identified a relationship between motor disorders, emotional and behavioral responses underlying aggressive responses to frustration.

In the behavior of children of the "nonconstructive" group, no differences were found depending on the situation content. R. Skinner, J. Piek (2001), based on their research, also believe that girls with motor disorder have lower self-esteem and higher anxiety level. In situations with peers, they more likely show independence than other girls. In situations with adults, they completely rely on them, and do not take up the situation with their own forces.

The opposite fact was also discovered. The "constructive" behavior in one boy was encountered only in situations with adults. In this case, the leading mode of behavior is apology and submission to the demands of adults (m: "I'm going out now," "Okay, let him play," "I won't be anymore"), etc. It should seem that this behavior speaks of the individual sensitivity, fear of non-compliance with norms, but the profile also contains intrapunitive responses, fixed on the satisfaction of the need, which indicates manifestations of independence and denies fear. In communication with peers, this child has dominated aggressive behavior, but consistent with the norm. According to the same aspects, these behavioral responses of P.M. Wehmeier, A. Schacht, and R.A. Barkley (2010) and A.F. Klassen, A. Miller, S. Fine (2004) are considered, who emphasize that such behavior may be based on social and communication difficulties.

Since submission to adult behavior is normatively high in society, and the elementary school child wants to be socially competent, then such behavior is fully justified, deserves the encouragement of adults and contributes to emotional well-being. M. Schoemaker, A. Kalverboer (1994); J. Noordstar, M. Volman (2020) share the same opinion, and in their paper they also argue that children with motor disorder are more introverted, less competent precisely in the social sphere focused on criterion behavior. This also explains the predominance of "constructive" behavior in the majority of children in situations of interaction with adults. The use of various tactics for mastering a difficult situation also distinguishes the children of the "constructive" group from each other. The degree of behavior "constructiveness" in difficult situations is associated with a certain level of well-being in personality development. In this regard, we carried out further study of the psychological make-up of children with motor disorders based on a comparative analysis of the selected children groups.

The analysis of the presented results indicates that it is possible to note some specificity in the attitude of children of the studied groups to the teacher. If we observe predominance of positive 
judgments over negative in all situations in children of group I, though it is slight, then the opposite situation is observed in group II, except for the situation of being late for class.

Thus, the data of the "school anxiety" test, namely in the situation of interaction with the teacher outside the class, convince us that the representatives of group I have established respectful and trusting relations with the teacher. Positive judgments in this situation in group I are expressed significantly more often. However, it should be noted that the situation interpretation by "non-constructive" children, if they use negative judgments about the teacher, is reduced to the teacher's assessment of educational activities and behavior, (for example: "The teacher will scold for running, he will ride someone down"). There is no direct expression of fear or feelings of threats from the teacher in any of the cases. The last statement is also true for the other two situations. It should be noted that statistically significant differences in the number of judgments of negative and positive modality, both in other situations and in the general indicator, were not identified between the studied groups.

The presented results give reason to consider that the children of group I have a clearly expressed positive attitude towards the teacher with a general rather positive background of teacher perception by children of both groups. Based on the comparison of the listed experimental data, it can be said that the majority of children with motor disorders, regardless of their belonging to the selected groups, perceive teachers quite positively, experiencing insignificant anxiety only in specific situations of interaction directly in the process of educational activity. In this case, one may note a clear expression of positive and trusting attitude towards the teacher in group I. In group II, there are children with indicators of negative perception of the teacher.

\section{Conclusions}

The comparison of all obtained data allowed us to reveal that two variants in the personality development of elementary school children with motor activity disorders: favorable and unfavorable. The children with a favorable variant of personality development are characterized by the predominance of "constructive" social behavior from a deprived background. When faced with social difficulties, they develop behavior forms that allow to overcome them, take on the resolution themselves or call for help of other people. Such children are optimistic about the world, adapt well in it, have a positive mode, are satisfied with their position in the system of family relationship, have established trusting relationships with teachers, accept and assess themselves and society positively. They compensate for educational difficulties by striking success in individual academic subjects not directly related to motor skills, as well as in various types of extracurricular activities. The children are characterized by emotional wellbeing, equally typical for their relationship to the world, society, and themselves. Emotional wellbeing, however, does not exclude experience failure in specific activities. Children in this group may experience negative feelings about educational difficulties, objectively bad in certain academic subjects directly related to motor skills, relationships with peers who do not involve them in the game due to motor clumsiness, about relationships with a teacher who is lightly indicates developmental deficiencies. These children have a knowing of all their difficulties, there is some anxiety in relation to school, adults and the world in general, but there is no spread distress. Their vitality allows them not to ignore failure, but to accept and overcome it, actively mastering the social situation. Parents perceive such children positively and are loyal to their difficulties. An unfavorable development variant can be considered the personality development in children who are distinguished by pronounced aggressive or avoidant "non-constructive" behavior in difficult situations, a high level of school anxiety, which extends not only to situations of failure in educational activities, but also to relations with a teacher and school in general.

\section{Bibliographic references}

Adolph, K.E., \& Hoch, J.E. (2019). Motor development: embodied, embedded, enculturated, and enabling. Annual Review of Psychology, 70, 141-164.

Cantell, M., Smyth M., \& Ahonen, T. (1994). Clumsiness in adolescence: educational, motor and social outcomes of motor delay detected at 5 years. Adapted Physical Activity Quarterly, 11(2), 115-129.

Corbetta, D. (2010). Understanding motor development from a multileveled approach. Journal of Sport \& Exercise Psychology, 32, pp S4-S4.

Cummins, A., Piek J.P., \& Dyck, M.J. (2005). Motor coordination, empathy, and social behaviour in school-aged children. 
Developmental Medicine and Child Neurology, 47(7), 437-442.

Diamond, A. (2000). Close interrelation of motor development and cognitive development and of the cerebellum and prefrontal cortex. Child Development, 71(1), 44-56.

Downing, C., \& Caravolas, M. (2020). Prevalence and cognitive profiles of children with comorbid literacy and motor disorders. Frontiers in Psychology, 11, 573580.

Francis, M., \& Piek, J. (2003). The effects of perceived social support and self-worth on depressive symptomatology in children with and without developmental coordination disorder. In Proceedings of the 38th APS Annual Conference, 2-5 October 2003 (pp. 70-74). Melbourne: The Australian Psychological Society.

Fulceri, F., Grossi, E., Contaldo, A., Narzisi, A., Apicella, F., Parrini, I., Tancredi, R., Calderoni, S., \& Muratori, F. (2019). Motor skills as moderators of core symptoms in autism spectrum disorders: preliminary data from an exploratory analysis with artificial neural networks. Frontiers in Psychology, 9, 2683.

Gasser-Haas, O., Sticca, F., \& Seiler, C.W. (2020). Poor motor performance - Do peers matter? Examining the role of peer relations in the context of the environmental stress hypothesis. Frontiers in psychology, 11, p 498.

Gerber, R.J., Wilks, T., \& Erdie-Lalena, C. (2010). Developmental milestones: Motor development. Pediatrics in Review, 31(7), 267277.

Goodway, J.D., Ozmun, J.C., \& Gallahue, D.L. (2019). Understanding Motor Development: Infants, Children, Adolescents, Adults. Burlington: Jones \& Bartlett Learning.

Green, D., Baird, G., \& Sugden, D. (2006). A pilot study of psychopathology in developmental coordination disorder. Child Care Health and Development, 32, 741-750.

Heiman, C.M., Cole, W.G., Lee, D.K., \& Adolph, K.E. (2019). Object interaction and walking: integration of old and new skills in infant development. Infancy, 24(4), 547-569.

Jansen, P., Quaiser-Pohl, C., Neuburger, S., Ruthsatz, V. (2015). Factors influencing mentalrotation with action-based gender-stereotyped objects-the role of fine motor skills. Current Psychology, 34(2), 466-476.

King-Dowling, S., Kwan, M.Y.W., Rodriguez, C., Missiuna, C., Timmons, B.W., \& Cairney, J. (2019). Physical activity in young children at risk for developmental coordination disorder. Developmental Medicine and Child Neurology, 61(11), 1302-1308.

Klassen, A.F., Miller, A., Fine, S. (2004). Healthrelated quality of life in children and adolescents who have a diagnosis of attentiondeficit/hyperactivity disorder. Pediatrics, 114(5), E541-E547.

Kopp, C.B. (2011). Development in the early years: socialization, motor development, and consciousness. Annual Review of Psychology, 62, 165-187.

Krombholz, H. (2018). Motor development and handedness in infants. Journal of Developmental and Educational Psychology, 50(2), 61-70.

Lee, K., Kim, Y.H., Lee, Y. (2020). Correlation between motor coordination skills and emotional and behavioral difficulties in children with and without developmental coordination disorder. International Journal of Environmental Research and Public Health, 17(20), 7362.

Lezak, M., Howieson, D., Loring, D., Hannay, H., \& Fischer, J. (2004). Neuropsychological Assessment. 4th ed. New York: Oxford University Press.

Lord, R., \& Hulme, C. (1987). Perceptual judgments of normal and clumsy children. Developmental Medicine and Child Neurology, 29(2), 250-257.

Losse, A., Henderson, S., Elliman, D., Hall, D., Knight, E., \& Jongmans, M. (1991). Clumsiness in children: do they grow out of it? A 10-year follow-up study. Developmental Medicine and Child Neurology, 33(1), 55-68.

Mokobane, M., Pillay, B.J., \& Meyer, A. (2019). Fine motor deficits and attention deficit hyperactivity disorder in primary school children. South African Journal of Psychiatry, 25, a1232.

Noordstar, J.J., \& Volman, M.J. (2020). Selfperceptions in children with probable developmental coordination disorder with and without overweight. Research in Developmental Disabilities, 99, 103601.

Ozeretsky, N.I. (1930) Methods of Motor Skills Research. Moscow-Leningrad: State Medical Publishing House.

Piek, J., Dawson, L., Smith, L., \& Gasson, N. (2008). The role of early fine and gross motor development on later motor and cognitive ability. Human Movement Science, 27(5), 668-681.

Poulsen, A.A., Ziviani, J.M., Cuskelly, M., \& Smith, R. (2007). Boys with developmental coordination disorder: loneliness and team sports participation. American Journal of Occupational Therapy, 61(4), 451-462.

Provost, B., Lopez, R., \& Heimerl, S. (2007). A comparison of motor delays in young children: autism spectrum disorder, developmental delay, and developmental concerns. Journal of Autism and Developmental Disorders, 37(2), 321-328. 
Rahimi-Golkhandan, S., Steenbergen, B., Piek, J.P., \& Wilson, P.H. (2014). Deficits of hot executive function in developmental coordination disorder: sensitivity to positive social cues. Human Movement Science, 38, 209-224.

Rigoli, D., \& Piek, J.P. (2020). Motor disorders biology. In S. Hupp and J. Jewell (Eds.), The Encyclopedia of Child and Adolescent Development, 10 volume set (vol. 8, pp. 1-12). Hoboken, NJ: John Wiley \& Sons.

Rosenbaum, D.A. (2005). The Cinderella of psychology: the neglect of motor control in the science of mental life and behavior. American Psychologist, 60(4), 308-317.

Rosenzweig, S. (1945). The picture-association method and its application in a study of reactions to frustration. Journal of Personality, 14, 3-23. Schabos, O., Hoffmann, K., Enzi, B., Juckel, G., \& Mavrogiorgou, P. (2019). Kinematic analysis of handwriting movements in individuals with intellectual disabilities with and without obsessive compulsive symptoms. Psychopathology, 52(6), 346-357.

Schoemaker, M., \& Kalverboer, A. (1994). Social and affective problems of children who are clumsy: How early do they begin. Adapted Physical Activity Quarterly, 11(2), 130-140.
Skinner, E.A., \& Zimmer-Gembeck, M.J. (2020). The Development of Coping during Infancy and Early Childhood. Encyclopedia of Infant and Early Childhood Development, vol.1, 2nd edn (pp. 417-429). Amsterdam: Elsevier.

Skinner, R., \& Piek, J. (2001). Psychosocial implications of poor motor control coordination in children and adolescents. Human Movement Science, 20(1-2), 73-94.

Van der Walt, J., Plastow, N.A., \& Unger, M. (2020). Motor skill intervention for pre-school children: A scoping review. African Journal of Disability, 9, a747.

Von Hofsten, C. (2004). An action perspective on motor development. Trends in Cognitive Sciences, 8(6), 266-272.

Wagner, M.O., Bös, K., Jascenoka, J., Jekauc, D., \& Petermann, F. (2012). Peer problems mediate the relationship between developmental coordination disorder and behavioral problems in school-aged children. Research in Developmental Disabilities, 33(6), 2072-2079.

Wehmeier, P.M., Schacht, A., \& Barkley, R.A. (2010). Social and emotional impairment in children and adolescents with ADHD and the impact on quality of life. Journal of Adolescent Health, 46(3), 209-217. 